\title{
Novel functional copolymers of vinyl acetate: 1. Alkyl ring-substituted ethyl 2-cyano-3-phenyl-2-propenoates
}

Benjamin Y. Killam, Rima T. Barkauskas, Daniel P. Dembiec, Rebecca S. Farrell, Maritza A. Gallego, Kelly A. Kaiser, Michelle L. Keeling, Kari Y. Kang, Gretchen R. Verdoorn, and Gregory B. Kharas

DePaul University, Chemistry and Biochemistry Department, 1110 West Belden Avenue, Chicago, IL 60614-3214

Alkyl ring-substituted ethyl 2-cyano-3-phenyl-2-propenoates, $\mathrm{RPhCH}=\mathrm{C}(\mathrm{CN}) \mathrm{CO}_{2} \mathrm{C}_{2} \mathrm{H}_{5}$ (where R is 2-methyl, 3-methyl, 4-methyl, 4-ethyl, 4-isopropyl, 4-t-butyl, 4-trifluoromethyl, 2-trifluoromethyl) were prepared and copolymerized with vinyl acetate in solution with radical initiation. The compositions of the copolymers were calculated from nitrogen analysis and the structures were analyzed by IR, ${ }^{1} \mathrm{H}$ and ${ }^{13} \mathrm{C}-\mathrm{NMR}$. Thermal behavior of the copolymers was studied by DSC and TGA. Decomposition of the copolymers in nitrogen occurred in two steps, first in the $200-500^{\circ} \mathrm{C}$ range with residue (13-16 wt $\left.\%\right)$, which then decomposed in the $500-800^{\circ} \mathrm{C}$ range. 


\section{Introduction}

Synthetic manipulation of polymer substrates via copolymerization is one of the oldest and most reliable methods to increase the functional diversity of soft materials [1]. Ringsubstituted ethyl 2-cyano-3-phenyl-2-propenoates (ECPP), $\mathrm{RPhCH}=\mathrm{C}(\mathrm{CN}) \mathrm{CO}_{2} \mathrm{C}_{2} \mathrm{H}_{5}$ continue to attract attention as comonomers for modification of commercial polymers. Ring unsubstituted ECPP has been copolymerized with acrylonitrile [2], styrene [3], vinyl acetate [4, 5], acrylic esters [6], and 1,2-ethanediyl ester of 2-methylpropenoic acid [7]. Terpolymerization of ECPP was reported with acrylonitrile and styrene [8], and ethyl acrylate and styrene [9]. Also reported are curable adhesive and coating compositions containing trifunctional olefinic monomers, including ECPP [10].

In continuation of our exploration of synthesis and radical copolymerization of esters 2-cyano-3-phenyl-2-propenoic acid, we have prepared alkyl ring-substituted ethyl 2-cyano3-phenyl-2-propenoates, $\mathrm{RPhCH}=\mathrm{C}(\mathrm{CN}) \mathrm{CO}_{2} \mathrm{C}_{2} \mathrm{H}_{5}$ (ECPP), where $\mathrm{R}$ is 2-methyl, 3-methyl, 4-methyl, 4-ethyl, 4-isopropyl, 4-t-butyl, 1,1,1-trifluoro-4-methyl, 1,1,1-trifluoro-2-methyl, and explore the feasibility of their copolymerization with vinyl acetate. There are reports of syntheses of 2-methyl, 3-methyl, 4-methyl [11], 4-ethyl, 4-isopropyl, 4-t-butyl [12], 4trifluoromethyl [13], and 2-trifluoromethyl [14] ring-substituted ECPP. To the best of our knowledge, there have been no reports on copolymerization of these ethyl 2-cyano-3phenyl-2-propenoates with vinyl acetate [15].

\section{Experimental}




\subsection{Materials}

2-Methyl, 3-methyl, 4-methyl, 4-ethyl, 4-isopropyl, 4-t-butyl, 4-trifluoromethyl, 2-

trifluoromethyl - substituted benzaldehydes, propyl cyanoacetate, piperidine, vinyl acetate, 1,1'-azobiscyclohexanecarbonitrile, $(\mathrm{ABCN})$, and toluene supplied from Sigma-Aldrich Co., were used as received.

\subsection{Instrumentation}

Infrared spectra of the ECPP monomers and copolymers ( $\mathrm{NaCl}$ plates) were determined with an ABB FTLA 2000 FT-IR spectrometer. The melting points of the monomers, the glass transition temperatures $\left(T_{\mathrm{g}}\right)$, of the copolymers were measured with TA (Thermal Analysis, Inc.) Model Q10 differential scanning calorimeter (DSC). The thermal scans were performed in a 25 to $200^{\circ} \mathrm{C}$ range at heating rate of $10^{\circ} \mathrm{C} / \mathrm{min}$. $T_{\mathrm{g}}$ was taken as a midpoint of a straight line between the inflection of the peak's onset and endpoint. The thermal stability of the copolymers was measured by thermogravimetric analyzer (TGA) TA Model Q50 from ambient temperature to $800^{\circ} \mathrm{C}$ at $20^{\circ} \mathrm{C} / \mathrm{min}$. The molecular weights of the polymers was determined relative to polystyrene standards in THF solutions with sample concentrations $0.8 \%(\mathrm{w} / \mathrm{v})$ by gel permeation chromatography (GPC) using a Altech 426 HPLC pump at an elution rate of $1.0 \mathrm{~mL} / \mathrm{min}$; Phenogel $5 \mu$ Linear column at $25^{\circ} \mathrm{C}$ and Viscotek 302 detector. ${ }^{1} \mathrm{H}$ - and ${ }^{13} \mathrm{C}-\mathrm{NMR}$ spectra were obtained on 10-25\% (w/v) monomer or polymer solutions in $\mathrm{CDCl}_{3}$ at ambient temperature using Avance $300 \mathrm{MHz}$ spectrometer. Elemental analyses were performed by Midwest Microlab, LLC (IN).

\subsection{Synthesis of Monomers}


The ring-substituted ethyl 2-cyano-3-phenyl-2-propenoates (ECPP) were synthesized by Knoevenagel condensation [16] of a ring-substituted benzaldehydes with ethyl cyanoacetate, catalyzed by base, piperidine.

\section{$\mathrm{RPhCHO}+\mathrm{NCCH}_{2} \mathrm{CO}_{2} \mathrm{C}_{2} \mathrm{H}_{5} \rightarrow \mathrm{RPhCH}=\mathrm{C}(\mathrm{CN}) \mathrm{CO}_{2} \mathrm{C}_{2} \mathrm{H}_{5}$}

where R is 2-methyl, 3-methyl, 4-methyl, 4-ethyl, 4-isopropyl, 4-t-butyl, 4-trifluoromethyl, 2-trifluoromethyl.

The preparation procedure was essentially the same for all the monomers. In a typical synthesis, equimolar amounts of ethyl cyanoacetate and an appropriate ringsubstituted benzaldehyde were mixed in equimolar ratio in a $20 \mathrm{~mL}$ vial. A few drops of piperidine were added with stirring. The product of the reaction was isolated by filtration and purified by crystallization from 2-propanol. The condensation reaction proceeded smoothly, yielding products, which were purified by conventional techniques.

\subsubsection{Ethyl 2-cyano-3-(2-methylphenyl)-2-propenoate}

Yield 74\%; mp $63^{\circ} \mathrm{C},{ }^{1} \mathrm{H}-\mathrm{NMR} \delta 8.6(\mathrm{~s}, 1 \mathrm{H}, \mathrm{CH}=), 8.2-7.1(\mathrm{~m}, 4 \mathrm{H}, \mathrm{Ph}), 4.3$ (q, $2 \mathrm{H}$, $\left.\mathrm{OCH}_{2}\right), 2.5\left(\mathrm{~s}, 3 \mathrm{H}, \mathrm{PhCH}_{3}\right), 1.4\left(\mathrm{t}, 3 \mathrm{H}, \mathrm{OCH}_{2} \underline{\mathrm{C}}_{3}\right) ;{ }^{13} \mathrm{C}-\mathrm{NMR} \delta 162(\mathrm{C}=\mathrm{O}), 153(\mathrm{HC}=)$, 140, 133, 131, 129, 128, $127(\mathrm{Ph}), 115(\mathrm{CN}), 105(\mathrm{C}=), 63\left(\mathrm{OCH}_{2}\right), 20\left(\mathrm{PhCH}_{3}\right), 14$ $\left(\mathrm{OCH}_{2} \underline{\mathrm{CH}}_{3}\right)$; IR $\left(\mathrm{cm}^{-1}\right): 3011-2830$ (m, C-H), 2223 (m, CN), 1741 (s, C=O), $1594(\mathrm{C}=\mathrm{C})$, 1254 (s, C-O-CH3), 799 (s, C-H out of plane). Anal. Calcd. for $\mathrm{C}_{13} \mathrm{H}_{13} \mathrm{NO}_{2}: \mathrm{C}, 72.54 ; \mathrm{H}$, $6.09 ; \mathrm{N}, 6.51$; Found: C, 71.79; H, 6.09; N, 6.53. 


\subsubsection{Ethyl 2-cyano-3-(3-methylphenyl)-2-propenoate}

Yield 72\%; mp 91.6 ${ }^{\circ} \mathrm{C},{ }^{1} \mathrm{H}-\mathrm{NMR} \delta 8.2(\mathrm{~s}, 1 \mathrm{H}, \mathrm{CH}=), 7.1-6.3(\mathrm{~m}, 4 \mathrm{H}, \mathrm{Ph}), 4.3(\mathrm{q}, 2 \mathrm{H}$, $\left.\mathrm{OCH}_{2}\right), 2.3\left(\mathrm{~s}, 3 \mathrm{H}, \mathrm{PhCH}_{3}\right), 1.3\left(\mathrm{t}, 3 \mathrm{H}, \mathrm{OCH}_{2} \underline{\mathrm{H}}_{3}\right) ;{ }^{13} \mathrm{C}-\mathrm{NMR} \delta 163(\mathrm{C}=\mathrm{O}), 153(\mathrm{HC}=)$, 138, 137, 133, 131, 129, $126(\mathrm{Ph}), 116(\mathrm{CN}), 104(\mathrm{C}=), 61\left(\mathrm{OCH}_{2}\right), 21\left(\mathrm{PhCH}_{3}\right), 14$ $\left(\mathrm{OCH}_{2} \underline{\mathrm{CH}}_{3}\right)$; IR $\left(\mathrm{cm}^{-1}\right)$ : 3041-2834 (m, C-H), 2224 (m, CN), 1727 (s, C=O), $1582(\mathrm{C}=\mathrm{C})$, 1240 (s, C-O-CH 3 ), 864 (s, C-H out of plane). Anal. Calcd. for $\mathrm{C}_{13} \mathrm{H}_{13} \mathrm{NO}_{2}: \mathrm{C}, 72.54 ; \mathrm{H}$, $6.09 ;$ N, 6.51; Found: C, 72.23; H, 6.08; N, 6.50.

\subsubsection{Ethyl 2-cyano-3-(4-methylphenyl)-2-propenoate}

Yield $83 \%$; mp $99.9^{\circ} \mathrm{C},{ }^{1} \mathrm{H}-\mathrm{NMR} \delta 8.4(\mathrm{~s}, 1 \mathrm{H}, \mathrm{CH}=), 7.8,7.0(\mathrm{~d}, 4 \mathrm{H}, \mathrm{Ph}), 4.3(\mathrm{q}, 2 \mathrm{H}$, $\left.\mathrm{OCH}_{2}\right), 2.3\left(\mathrm{t}, 3 \mathrm{H}, \mathrm{PhCH}_{3}\right), 1.3\left(\mathrm{t}, 3 \mathrm{H}, \mathrm{OCH}_{2} \mathrm{C}_{3}\right) ;{ }^{13} \mathrm{C}-\mathrm{NMR} \delta 163(\mathrm{C}=\mathrm{O}), 155(\mathrm{HC}=)$, 145, 131, 130, $129(\mathrm{Ph}), 116(\mathrm{CN}), 102(\mathrm{C}=), 62\left(\mathrm{OCH}_{2}\right), 22\left(\mathrm{PhCH}_{3}\right), 14\left(\mathrm{OCH}_{2} \mathrm{CH}_{3}\right)$; IR (cm $\left.{ }^{-1}\right): 3031-2924$ (m, C-H), 2225 (m, CN), 1742 (s, C=O), 1234 (s, C-O-C), 847, 759 (s, C-H out of plane). Anal. Calcd. for $\mathrm{C}_{13} \mathrm{H}_{13} \mathrm{NO}_{2}$ : C, 72.54; H, 6.09; N, 6.51; Found: C, 72.19; H, 6.12; N, 6.34.

\subsubsection{Ethyl 2-cyano-3-(4-ethylphenyl)-2-propenoate}

Yield 79\%; ${ }^{1} \mathrm{H}-\mathrm{NMR} \delta 8.3(\mathrm{~s}, 1 \mathrm{H}, \mathrm{CH}=), 7.9,7.3(\mathrm{~d}, 4 \mathrm{H}, \mathrm{Ph}), 4.4$ (q, 2H, $\left.\mathrm{OCH}_{2}\right), 2.7$ (q, $\left.2 \mathrm{H}, \mathrm{PhCH}_{2}\right), 1.4\left(\mathrm{t}, 3 \mathrm{H}, \mathrm{OCH}_{2} \underline{\mathrm{CH}}_{3}\right), 1.2\left(\mathrm{t}, 3 \mathrm{H}, \mathrm{PhCH}_{2} \mathrm{CH}_{3}\right) ;{ }^{13} \mathrm{C}-\mathrm{NMR} \delta 163(\mathrm{C}=\mathrm{O}), 151$ $(\mathrm{HC}=), 154,131,130,129,128(\mathrm{Ph}), 116(\mathrm{CN}), 102(\mathrm{C}=), 63\left(\mathrm{OCH}_{2}\right), 29\left(\mathrm{PhCH}_{2}\right), 16$ $\left(\mathrm{PhCH}_{2} \underline{\mathrm{CH}}_{3}\right), 14\left(\mathrm{OCH}_{2} \underline{\mathrm{CH}}_{3}\right) ; \mathrm{IR}\left(\mathrm{cm}^{-1}\right): 3100-2825$ (m, C-H), 2220 (m, CN), 1720 (s, $\mathrm{C}=\mathrm{O}), 1609$ (C=C), 1248 (s, C-O-C), 840 (s, C-H out of plane). Anal. Calcd. for $\mathrm{C}_{14} \mathrm{H}_{15} \mathrm{NO}_{2}$ : C, 73.34; H, 6.59; N, 6.11; Found: C, 72.89; H, 6.39; N, 5.89. 


\subsubsection{Ethyl 2-cyano-3-(4-isopropylphenyl)-2-propenoate}

Yield 74\%; ${ }^{1} \mathrm{H}-\mathrm{NMR} \delta 8.2(\mathrm{~s}, 1 \mathrm{H}, \mathrm{CH}=), 7.9,7.3(\mathrm{~m}, 4 \mathrm{H}, \mathrm{Ph}), 4.4\left(\mathrm{q}, 2 \mathrm{H}, \mathrm{OCH}_{2}\right), 2.9(\mathrm{~m}$, $1 \mathrm{H}, \mathrm{PhCH}), 1.3\left(\mathrm{t}, 3 \mathrm{H}, \mathrm{OCH}_{2} \mathrm{CH}_{3}\right), 1.2\left(\mathrm{~d}, 6 \mathrm{H}, \mathrm{CH}\left(\mathrm{CH}_{3}\right)_{2} ;{ }^{13} \mathrm{C}-\mathrm{NMR} \delta 163(\mathrm{C}=\mathrm{O}), 153\right.$ $(\mathrm{HC}=)$, 132, 130, 129, $127(\mathrm{Ph}), 116(\mathrm{CN}), 103(\mathrm{C}=), 63\left(\mathrm{OCH}_{2}\right), 34(\mathrm{PhCH}), 24$ $\left(\mathrm{PhCH}\left(\underline{\mathrm{CH}}_{3}\right)_{2}, 14\left(\mathrm{OCH}_{2} \underline{\mathrm{CH}}_{3}\right) ; \mathrm{IR}\left(\mathrm{cm}^{-1}\right):\right.$ 3028-2814 (m, C-H), 2223 (m, CN), 1725 (s, $\mathrm{C}=\mathrm{O}), 1597(\mathrm{C}=\mathrm{C}), 1268$ (s, C-O-C), 828 (s, C-H out of plane). Anal. Calcd. for $\mathrm{C}_{15} \mathrm{H}_{17} \mathrm{NO}_{2}$ : C, 74.05; H, 7.04; N, 5.76; Found: C, 73.61; H, 7.06; N, 5.97.

\subsubsection{Ethyl 2-cyano-3-(4-t-butylphenyl)-2-propenoate}

Yield 83\%; mp 62.2C $;{ }^{\circ} \mathrm{H}-\mathrm{NMR} \delta 8.2(\mathrm{~s}, 1 \mathrm{H}, \mathrm{CH}=), 7.8,7.4(\mathrm{~m}, 4 \mathrm{H}, \mathrm{Ph}), 4.3(\mathrm{q}, 2 \mathrm{H}$, $\left.\mathrm{OCH}_{2}\right), 1.3\left(\mathrm{~m}, 12 \mathrm{H}, \mathrm{CH}_{3}\right) ;{ }^{13} \mathrm{C}-\mathrm{NMR} \delta 162(\mathrm{C}=\mathrm{O}), 153(\mathrm{HC}=), 132,131,129,126(\mathrm{Ph})$, $116(\mathrm{CN}), 117(\mathrm{C}=), 61\left(\mathrm{OCH}_{2}\right), 34\left(\underline{\mathrm{CCH}}_{3}\right), 31\left(\mathrm{CCH}_{3}\right), 14\left(\mathrm{CH}_{2} \underline{\mathrm{CH}_{3}}\right)$; IR $\left(\mathrm{cm}^{-1}\right): 3022-$ 2867 (m, C-H), 2221 (m, CN), 1720 (s, C=O), 1589 (C=C), 1220 (s, C-O-C), 811, 753 (s, C-H out of plane). Anal. Calcd. for $\mathrm{C}_{16} \mathrm{H}_{19} \mathrm{NO}_{2}$ : C, 74.68; H, 7.44; N, 5.44; Found: C, 75.01; H, 7.33; N, 5.83.

\subsubsection{Ethyl 2-cyano-3-[4-(trifluoromethyl)phenyl]-2-propenoate}

Yield $87 \%$; mp $116.5^{\circ} \mathrm{C} ;{ }^{1} \mathrm{H}-\mathrm{NMR} \delta 8.2(\mathrm{~s}, 1 \mathrm{H}, \mathrm{CH}=), 7.9-7.7(\mathrm{~m}, 4 \mathrm{H}, \mathrm{Ph}), 4.3(\mathrm{q}, 2 \mathrm{H}$, $\left.\mathrm{OCH}_{2}\right), 1.3\left(\mathrm{t}, 3 \mathrm{H}, \mathrm{OCH}_{2} \underline{\mathrm{H}}_{3}\right) ;{ }^{13} \mathrm{C}-\mathrm{NMR} \delta 163(\mathrm{C}=\mathrm{O}), 153(\mathrm{HC}=), 132,131,129,126$ $(\mathrm{Ph}), 116(\mathrm{CN}), 124\left(\mathrm{CF}_{3}\right), 117(\mathrm{C}=), 61\left(\mathrm{OCH}_{2}\right), 14\left(\mathrm{OCH}_{2} \underline{\mathrm{CH}_{3}}\right) ; \mathrm{IR}\left(\mathrm{cm}^{-1}\right): 3056-2842$ (m, C-H), 2224 (m, CN), 1741 (s, C=O), 1598 (C=C), 1223 (s, C-O-C), 865 (s, C-H out of plane). Anal. Calcd. for $\mathrm{C}_{13} \mathrm{H}_{10} \mathrm{~F}_{3} \mathrm{NO}_{2}$ : C, 58.00; H, 3.74; N, 5.20; Found: C, 58.02; H, $3.68 ; \mathrm{N}, 5.11$. 


\subsubsection{Ethyl 2-cyano-3-[2-(trifluoromethyl)phenyl]-2-propenoate}

Yield 72\%; mp $114.2^{\circ} \mathrm{C} ;{ }^{1} \mathrm{H}-\mathrm{NMR} \delta 8.6(\mathrm{~s}, 1 \mathrm{H}, \mathrm{CH}=), 7.9-7.1(\mathrm{~m}, 4 \mathrm{H}, \mathrm{Ph}), 4.3(\mathrm{q}, 2 \mathrm{H}$, $\left.\mathrm{OCH}_{2}\right), 1.3\left(\mathrm{t}, 3 \mathrm{H}, \mathrm{OCH}_{2} \mathrm{C}_{3}\right) ;{ }^{13} \mathrm{C}-\mathrm{NMR} \delta 163(\mathrm{C}=\mathrm{O}), 153(\mathrm{HC}=), 140,133,129,127$, $126(\mathrm{Ph}), 116(\mathrm{CN}), 123\left(\mathrm{CF}_{3}\right), 105(\mathrm{C}=), 61\left(\mathrm{OCH}_{2}\right), 14\left(\mathrm{OCH}_{2} \underline{\mathrm{CH}} 3\right)$; IR $\left(\mathrm{cm}^{-1}\right): 3061-$ 2854 (m, C-H), 2222 (m, CN), 1732 (s, C=O), 1567 (C=C), 1212 (s, C-O-C), 843 (s, C-H out of plane). Anal. Calcd. for $\mathrm{C}_{13} \mathrm{H}_{10} \mathrm{~F}_{3} \mathrm{NO}_{2}: \mathrm{C}, 58.00 ; \mathrm{H}, 3.74 ; \mathrm{N}, 5.20$; Found: C, 57.88; $\mathrm{H}, 3.76 ; \mathrm{N}, 5.13$.

\subsection{Copolymerization}

Copolymers of the VAC and the ECPP monomers were prepared in 25-mL glass screw cap vials at $\mathrm{VAC} / \mathrm{ECPP}=3(\mathrm{~mol})$ the monomer feed using $0.12 \mathrm{~mol} / \mathrm{L}$ of $\mathrm{ABCN}$ at an overall monomer concentration $2.44 \mathrm{~mol} / \mathrm{L}$ in $10 \mathrm{~mL}$ of toluene. The copolymerization was conducted at $70^{\circ} \mathrm{C}$. After a predetermined time, the mixture was cooled to room temperature, and precipitated dropwise in methanol. The composition of the copolymers was determined based on the nitrogen content.

\section{Results and Discussion}

\subsection{Homopolymerization}

An attempted homopolymerization of the ECPP compounds in the presence of ABCN did not produce any polymer as indicated by the lack of a precipitate in methanol. The inability of the compounds to polymerize is associated with steric difficulties encountered in homopolymerization of 1,1- and 1,2-disubstituted ethylenes [17]. Homopolymerization 
of VAC under conditions identical to those in copolymerization experiments yielded $24.8 \%$ of polyvinyl acetate, when polymerized for $60 \mathrm{~min}$.

\subsection{Copolymerization}

Copolymerization (Sch. 1) of VAC and the ring-substituted ECPP resulted in formation of copolymers (Table 1) with weight-average molecular masses 20 to $70 \mathrm{kD}$.

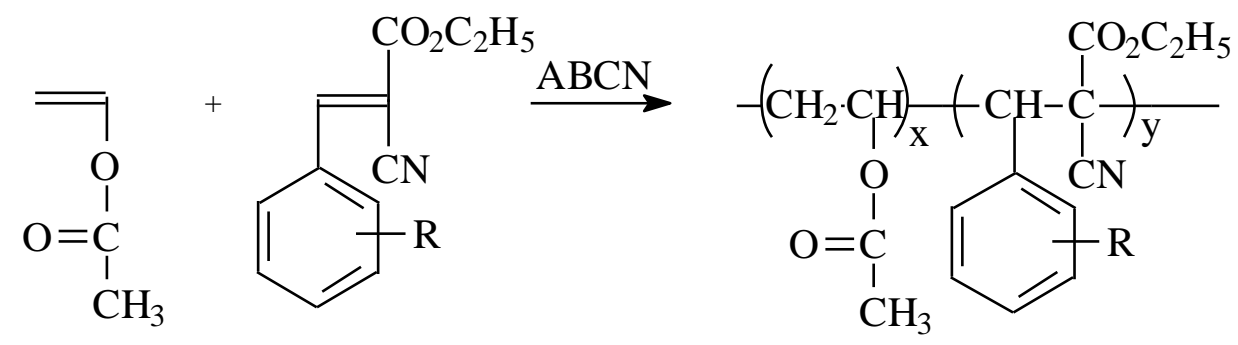

Sch. 1. Copolymerization of vinyl acetate and the ring-substituted propyl 2-cyano-3phenyl-2-propenoates, $\mathrm{RPhCH}=\mathrm{C}(\mathrm{CN}) \mathrm{CO}_{2} \mathrm{C}_{2} \mathrm{H}_{5}$. R is 2-methyl, 3-methyl, 4-methyl, 4ethyl, 4-isopropyl, 4-t-butyl, 4-trifluoromethyl, 2-trifluoromethyl.

According to the nitrogen elemental analysis, between 46.9 and 49.9 mol\% of TSE monomer is present in the copolymers prepared at VAC/ECPP $=3(\mathrm{~mol})$, which is indicative of relatively high reactivity of the monomers towards VAC. 
Table 1. Copolymerization of vinyl acetate and ring-substituted ethyl 2-cyano-3-phenyl2-propenoates, $\mathrm{RPhCH}=\mathrm{C}(\mathrm{CN}) \mathrm{CO}_{2} \mathrm{C}_{2} \mathrm{H}_{5}$.

\begin{tabular}{|l|c|l|l|l|l|c|c|c|c|}
\hline \multicolumn{1}{|c|}{$\mathrm{R}$} & $\begin{array}{c}\text { Yield } \\
\mathrm{a} \\
\mathrm{wt} \%\end{array}$ & $\begin{array}{c}\mathrm{N} \\
\mathrm{wt} \%\end{array}$ & $\begin{array}{c}\text { ECPP } \\
\text { in } \\
\text { copol., } \\
\mathrm{mol} \%\end{array}$ & $\begin{array}{c}\mathrm{M}_{\mathrm{w}} \\
\mathrm{kD}\end{array}$ & $\begin{array}{c}\mathrm{T}_{\mathrm{g}} \\
{ }^{\circ} \mathrm{C}\end{array}$ & $\begin{array}{c}\text { Onset } \\
\text { of } \\
\text { decom } \\
\mathrm{p} .,\end{array}$ & $\begin{array}{c}10 \% \\
\mathrm{wt} \\
\mathrm{loss}, \\
{ }^{\circ} \mathrm{C}\end{array}$ & $\begin{array}{l}50 \% \\
\mathrm{wt} \\
\text { loss, } \\
{ }^{\circ} \mathrm{C}\end{array}$ & $\begin{array}{c}\text { Residue } \\
\text { at } \\
500^{\circ} \mathrm{C}, \\
\mathrm{wt} \%\end{array}$ \\
\hline 2-Methyl & 13.1 & 4.36 & 49.5 & 43.2 & 87 & 201 & 278 & 344 & 13 \\
\hline 3-Methyl & 14.8 & 4.32 & 48.8 & 48.3 & 93 & 200 & 284 & 342 & 13 \\
\hline 4-Methyl & 13.7 & 4.33 & 49.0 & 55.5 & 91 & 177 & 264 & 340 & 16 \\
\hline 4-Ethyl & 15.6 & 4.2 & 49.9 & 42.9 & 101 & 178 & 269 & 342 & 14 \\
\hline 4-Isopropyl & 12.2 & 3.98 & 48.9 & 49.0 & 111 & 199 & 277 & 338 & 15 \\
\hline 4-tert-Butyl & 19.2 & 3.86 & 49.6 & 47.4 & 96 & 201 & 283 & 341 & 14 \\
\hline 4-Trifluoromethyl & 14.2 & 3.62 & 46.9 & 42.1 & 98 & 198 & 287 & 337 & 13 \\
\hline 2-Trifluoromethyl & 13.6 & 3.64 & 47.4 & 54.5 & 96 & 188 & 276 & 333 & 14 \\
\hline
\end{tabular}

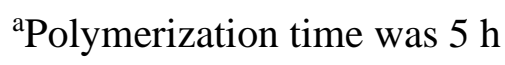

\subsection{Structure and Thermal Properties}

The structure of VAC-ECPP copolymers was characterized by IR and NMR spectroscopy.

A comparison of the spectra of the monomers, copolymers and polyvinyl acetate shows, that the reaction between the ECPP monomers and VAC is a copolymerization. 
IR spectra of the copolymers show overlapping bands in $3280-2700 \mathrm{~cm}^{-1}$ region corresponding to $\mathrm{C}-\mathrm{H}$ stretch vibrations. The bands for the ECPP monomer unit are 2232$2220(\mathrm{w}, \mathrm{CN}), 1750-1710(\mathrm{~s}, \mathrm{C}=\mathrm{O})$, and $1240-1220 \mathrm{~cm}^{-1}(\mathrm{~m}, \mathrm{C}-\mathrm{O})$. Benzene ring of ECPP monomers show ring stretching bands at $1520-1480$ and $1510-1460 \mathrm{~cm}^{-1}$ as well as a doublet 800-900, 820-700 $\mathrm{cm}^{-1}$, associated with C-H out of plane deformations. The absorptions of the VAC units appear at 1760-1740 $\mathrm{cm}^{-1}$ (carbonyl group), 1370-1360 $\mathrm{cm}^{-1}$ (wagging $\mathrm{CH}_{3}$ ), 1280-1220 $\mathrm{cm}^{-1}$ (stretching COO), 1010 and $1110 \mathrm{~cm}^{-1}$ (stretching C-C-C, These bands can be readily identified in VAC copolymers with TSE monomers containing cyano and carbonyl electron withdrawing groups.

The ${ }^{1} \mathrm{H}-\mathrm{NMR}$ spectra of the VAC-ECPP copolymers show a broad peak in a 7.2-6.8 ppm region corresponding to phenyl ring protons. The peak at $5.3 \mathrm{ppm}$ is assigned to the methine proton resonance of the VAC unit since the same signal is also observed in the spectra of polyvinyl acetate (PVAC) and various random and alternating copolymers of VAC [18]. A broad resonance at $4.2 \mathrm{ppm}$ is assigned to methylene protons of ECPP ethyl group. The two peaks in the region of 2.4-3.4 ppm are assigned to the methine proton of ECPP [5]. The resonance signal at $2.0 \mathrm{ppm}$ corresponds to absorbance of VAC methyl protons. The peak at $1.3 \mathrm{ppm}$ is assigned to the methyl protons of the ECPP unit. The protons of alkyl ring-substituted ECPP-VAC copolymers are observed as broad overlapping peaks at $2.3 \mathrm{ppm}$ for metha, orto, and para-substituted methyls, 2.6 and $1.2 \mathrm{ppm}$ for $\mathrm{CH}_{2}$ and $\mathrm{CH}_{3}$ of ethyl, $2.8 \mathrm{ppm}(\mathrm{CH})$ and $1.2 \mathrm{ppm}\left(\mathrm{CH}_{3}\right)$ of isopropyl, and $1.3 \mathrm{ppm}$ for $\mathrm{CH}_{3}$ of 4-tertbutyl. 
The ${ }^{13} \mathrm{C}$-NMR spectra also support the suggested skeletal structure of the copolymers. Thus, the assignment of the peaks is as follows: $164-160 \mathrm{ppm}(\mathrm{C}=\mathrm{O}), 158-134 \mathrm{ppm}$ (quaternary carbons of phenyls), 145-120 ppm (phenyl carbons), 120-110 ppm (CN), 60-50 ppm (alkoxy ECPP carbons), 72-66 ppm and 42-38 ppm (methylene and methine of VAC), 43-10 ppm - alkyl carbons of ECPP. Broadening of the NMR signals in the spectra of the copolymers is apparently associated with head-to-tail and head-to-head structures, which formed though the attack of a styrene-ended radical on both sides of TSE monomer (22). The IR and NMR data showed that these are true copolymers, composed of both TSE and ST monomer units.

The copolymers prepared in the present work are all soluble in ethyl acetate, THF, DMF and $\mathrm{CHCl}_{3}$ and insoluble in methanol, ethyl ether, and petroleum ether. They are amorphous and show no crystalline DSC endotherm. Results of thermal analysis of VACECPP copolymers are presented in Table 1. Relatively high $T_{g}$ of the copolymers in comparison with that of polyvinyl acetate $\left(T_{g}=28-31^{\circ} \mathrm{C}\right)$ indicates decrease of chain mobility of the copolymer due to the high dipolar character of the ECPP structural units. Information on the degradation of the copolymers was obtained from thermogravimetric analysis. Decomposition of the copolymers in nitrogen occurred in two steps, presumably acetic acid elimination in $190-350^{\circ} \mathrm{C}$ range followed by a more slow decomposition of formed residue (13-16 wt \%), which then decomposed in the $500-800^{\circ} \mathrm{C}$ range. The decomposition products were not analyzed in this study, and the mechanism has yet to be investigated. 


\section{Conclusions}

Alkyl ring-substituted ethyl 2-cyano-3-phenyl-2-propenoates were prepared and copolymerized with styrene. The compositions of the copolymers were calculated from nitrogen analysis and the structures were analyzed by IR, $\mathrm{H}^{1}$ and ${ }^{13} \mathrm{C}-\mathrm{NMR}$. The thermal gravimetric analysis indicated that the copolymers decompose in in two steps, first in the $200-500^{\circ} \mathrm{C}$ range with residue $(13-16 \mathrm{wt} \%)$, which then decomposed in the $500-800^{\circ} \mathrm{C}$ range.

\section{Acknowledgments}

The authors are grateful to acknowledge that the project was partly supported by the Chicago Society of Coating Technology.

\section{References}

[1] C-H Functionalization of Commodity Polymers. Jill B. Williamson, Sally E. Lewis, Robert R. Johnson III, Irene M. Manning, Assist. Prof. Frank A. Leibfarth. Angewandte Chemie. Intern. Ed. November 2018. https://doi.org/10.1002/anie.201810970

[2] Copolymerization of acrylonitrile. I. Copolymerization with styrene derivatives containing nitrile groups in the side chain. Ronel, Samuel H.; Kohn, David H. J. Polym. Sci., Part A-1: Polymer Chemistry (1969), 7(8), 2209-19. 
[3] Copolymerization of styrene. IV. Copolymerization with esters of benzylidenecyanoacetic acid. Gilath, Arie; Ronel, Samuel H.; Shmueli, Mirjam; Kohn, David H. J. Appl. Polym. Sci. (1970), 14(6), 1491-505.

[4] Copolymerization of Vinyl Acetate with Ethyl Cyanocinnamate. G.B. Kharas, Kohn, D.H., J. Polym. Sci.: Polym. Chem. Ed., 21, 1457 (1983).

[5] Characterization of copolymers of vinyl acetate with ethyl $\alpha$-cyanocinnamate Kharas, Gregory; Kohn, David H. J. Polym. Sci., Polym. Chem. Ed. (1984), 22(3), 577-82.

[6] Copolymerization of acrylic esters with ethyl $\alpha$-cyanocinnamate. Angelovici, Mose M.; Kohn, David H. J. Appl. Polym. Sci. (1990), 40(3-4), 485-94.

[7] Nitrile polymers as packings for chromatography. Asada, Nobuyuki Jpn. Kokai Tokkyo Koho (1988), JP 63135408 A 19880607.

[8] Terpolymerization studies. I. Terpolymerization of acrylonitrile, styrene, and esters of $\alpha$-cyanocinnamic acid. Ronel, Samuel H.; Kohn, David H. J. Appl. Polym. Sci. (1975), 19(9), 2359-77.

[9] Terpolymerization studies. IV. Terpolymerization of ethyl acrylate, ethyl $\alpha$ cyanocinnamate, and styrene. Angelovici, Mose M.; Kohn, David H. Journal of Applied Polymer Science (1991), 42(4), 1121-4.

[10] Curable adhesive and coating compositions containing trifunctional olefinic monomers and their application. Righettini, Robin F. PCT Int. Appl. (2000), WO 2000077079 A2 20001221. 
[11] Novel Copolymers of Alkyl and Alkoxy Ring-Substituted Ethyl 2-Cyano-3phenyl-2-propenoates and Styrene. Kharas, Gregory B.; Diener, Celeste A.; Barbarawi, Hadeal A.; Beavers, Nicole D.; Borovilos, Maria; Carney, Jason; Fox, Ashley A.; McClelland, Kristen M.; Gehle, Jessica L.; Yedlinski, Jason; et al Journal of Macromolecular Science, Pure and Applied Chemistry (2004), A41(8), 889-896.

[12] Novel Copolymers of Styrene. 4. Alkyl Ring-substituted Ethyl 2-Cyano-3-Phenyl2-Propenoates. Kharas, Gregory B.; Molina, Eric S.; Pierce, Erin E.; Cocjin, Sally Ann B.; Cruz, Christopher; Fair, Kimberly M.; Flaksman, Stephanie S.; Liggins, Mia J.; Meglei, Alex D.; Pantos, Marianna E.; et al. Journal of Macromolecular Science, Part A: Pure and Applied Chemistry (2013), 50(2), 144-148.

[13] Eco-friendly conjugate hydrocyanation of $\alpha$-cyanoacrylates using potassium hexacyanoferrate(II) as cyanating reagent. Zhang, Yu-Peng; Hu, Xiao-Chun; Li, Zheng. Chemical Papers (2015), 69(4), 596-603.

[14] Efficient and reusable amine-functionalized polyacrylonitrile fiber catalysts for Knoevenagel condensation in water. Li, Guowei; Xiao, Jia; Zhang, Wenqin. Green Chemistry (2012), 14(8), 2234-2242.

[15] SciFinder structure search accessed 2021-08-20.

[16] Smith, M. B., March, J. (2001) Addition to Carbon-Hetero Multiple Bonds, In March's Advanced Organic Chemistry; J. Wiley \& Sons: New York, Ch.16, 1225.

[17] Odian, G. Principles of Polymerization, 4th Ed., Wiley-Interscience: New York, 2004. 
[18] N. G. Kulkarni, N. Krishnamurty, P.C. Chaterjee, and M.A. Sivasamban, Makromol. Chem. 139, 165 (1970). 